\title{
Tecendo o Tupé: um estudo sobre percepção e interpretação ambiental na RDS do Tupé, Manaus-AM
}

\author{
Solange Barros* \\ Solange Terezinha de Lima Guimarães ${ }^{* *}$ \\ Jackson Fernando Rêgo ${ }^{* * *}$
}

\section{Resumo}

Temos na Amazônia, além da paisagem rica em biodiversidade uma riqueza de conhecimentos de povos que habitam de modo interativo essas paisagens e fazem delas seu meio de existência. Nosso trabalho tem por objetivo evidenciar os olhares e valores daqueles que habitam esse ambiente, tendo como estudo de caso os moradores da Reserva de Desenvolvimento Sustentável do Tupé, a oeste da cidade de Manaus-AM. Os estudos de percepção ambiental e geógrafos com orientação humanística apararam nossa perspectiva teórica. Os percursos de investigação foram orientados pela abordagem da pesquisa qualitativa e foram delimitadas estratégias como o trabalho de campo, a observação participante, as entrevistas semi-estruturadas. Os relatos evidenciam a ligação dos moradores do Tupé com esta paisagem: a vida no interior em contato com a natureza, o regime dos rios, a mata, os símbolos como a roça, a pesca, a calma, as festas, as dificuldades ligadas à infra-estrutura. Estas são dimensões materiais e simbólicas indispensáveis para o conhecimento desse lugar.

Palavras-chave: Espaço-lugar, mundo vivido, percepção, homemmeio ambiente, unidade de conservação.

* Geógrafa e Mestre em Ciências Florestais e Ambientais - UFAM / Manaus-AM (solange_barros@hotmail.com).

** Docente do Depto. de Geografia - IGCE/UNESP Rio Claro-SP, (hadra@olam.com.br).

*** Engenheiro Florestal, PPGG em Ciências Florestais e Ambientais do Depto. de Ciências Florestais da UFAM (jacksonrego@ufam.edu.br).

Geosul, Florianópolis, v. 23, n. 45, p 85-104, jan./jun. 2008 
BARROS, S. et al. Tecendo o Tupé: um estudo sobre percepção e ...

Weaving the Tupé: a study on environmental perception and interpretation in a sustainable development area (Tupé), Manaus-AM, Brazil

\begin{abstract}
In the Amazon, in addition to a landscape rich in biodiversity, there is the richness of knowledge of the peoples who live in and interact with this landscape by making their living out of it. The current work aims at highlighting the values and the viewpoints of those who dwell in the referred environment. It is developed by means of a case study which is based on the life of the inhabitants of a Sustainable Development Area (Tupé) located in western Manaus, Brazil. Our theoretical basis is supported by environmental and geographical perception studies oriented towards a humanistic point of view. The investigation path to be followed is in accordance with the qualitative research approach which includes strategies such as fieldwork, active observation and semi-structured interviews. The reports reveal that the Tupé dwellers have a bond with the landscape: the contact with nature, the movement of the rivers, the forest, the countryside symbols, fishing, silence, celebrations and infrastructural problems. Those material and symbolic dimensions are essential for the understanding of the place.
\end{abstract}

Key words: Space-place, lived world, perception, environmental man, conservation unit.

\title{
Introdução
}

Ao falarmos em Amazônia podemos ter diferentes tipos de enfoques: seus rios e densa vegetação, território de fronteira, lugar de conflitos entre índios, madeireiros e fazendeiros, área de mineração e de expansão de capital. Ainda passa a ser área de proteção e de preservação ambiental.

Entretanto, interagindo com essa paisagem temos povos que fazem dela seu meio e modo de existência. Populações que vivem às 
margens dos rios, próximas da floresta, estabelecendo sentimentos, experiências, técnicas e modos de se interar à natureza.

Nosso trabalho tem por objetivo evidenciar os olhares e valores dos moradores que habitam esse ambiente, tendo como estudo de caso duas comunidades no estado do Amazonas, a comunidade São João do Tupé e a comunidade Colônia Central na Reserva de Desenvolvimento Sustentável do Tupé.

Os fios começaram a ser tecidos através dos estudos de Percepção Ambiental que busca compreender os significados, os valores e as atitudes que regem as relações estabelecidas entre os moradores e o lugar aonde vivem captando riqueza de valores que dão sentidos aos lugares de vida do ser humano.

\section{Encontrando o Tupé}

$\mathrm{Na}$ língua tupi, a palavra Tupé significa entrançado, tecido trançado com talas do arumã, usado como objeto de arte e artesanato, tapete, esteira, dentre outras utilidades. Este termo também identifica uma área de 12.000 ha, localizada a Oeste da cidade de Manaus - Amazonas (Figura 1).

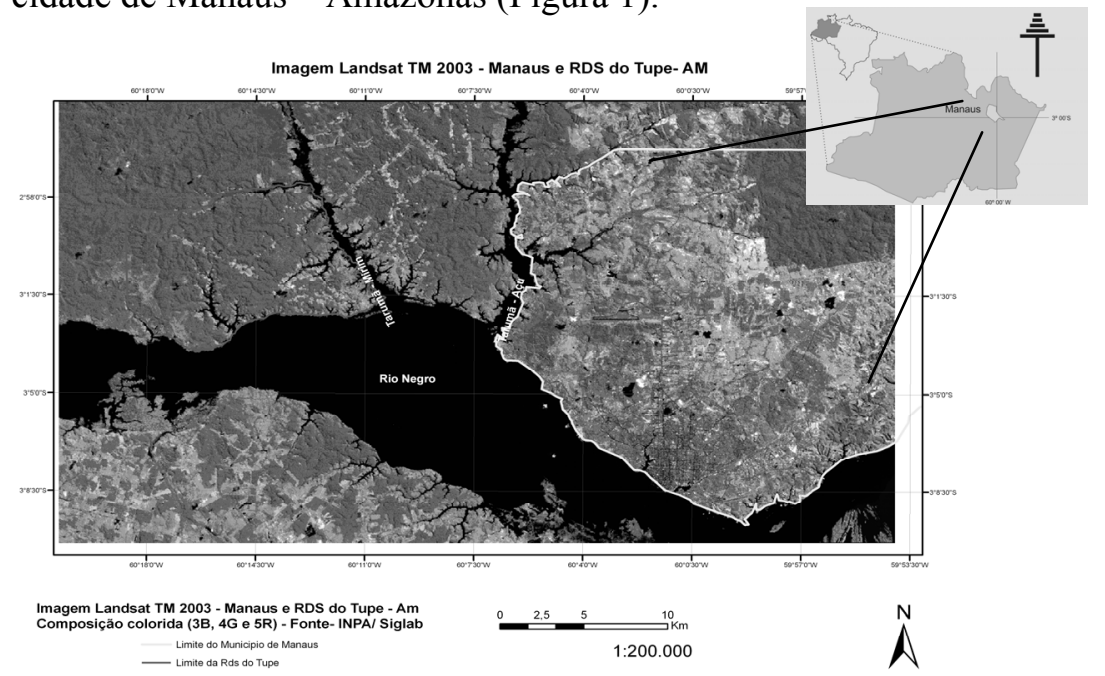

Figura 1- Localização da RDS do Tupé 
BARROS, S. et al. Tecendo o Tupé: um estudo sobre percepção e ...

Banhado permanentemente pelas águas do rio Negro, o Tupé encanta pelas suas belezas naturais que apresentam relevantes aspectos cênicos. Na época da cheia ocorre a inundação da floresta de igapó e na época de águas baixas suas praias são reveladas (Fig.2).

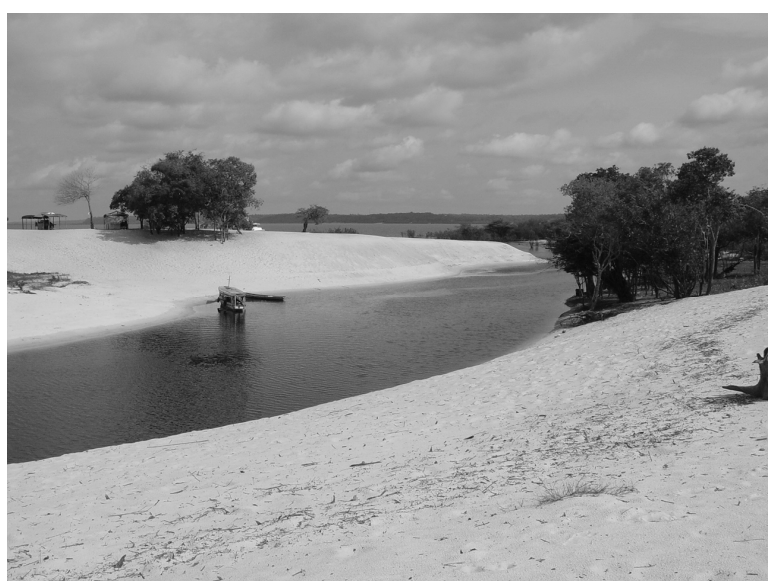

Figura 2- Vista parcial da praia do Tupé. Fonte: Barros, 2005.

Este cenário tem atraído um grande número de turistas e, pela facilidade de acesso, passou a sofrer acelerados e intensos impactos antrópicos. Em 2005 essa área passou a ser uma Reserva de Desenvolvimento Sustentável, integrando o sistema municipal de unidades de conservação conforme Decreto $\mathrm{N}^{\circ} 8044$.

O Tupé abriga seis comunidades ribeirinhas, tendo outras seis no seu entorno, com uma população total de 700 pessoas segundo a Secretaria de Meio Ambiente de Manaus. Tais comunidades estão dispersas entre si e o acesso, entre elas é feito principalmente por via fluvial.

Cada comunidade possui histórias, vivências que lhes são peculiares. Nosso trabalho analisou alguns dos aspectos de duas comunidades: a São João do Tupé e a Colônia Central (Fig. 3). 
BARROS, S. et al. Tecendo o Tupé: um estudo sobre percepção e ...

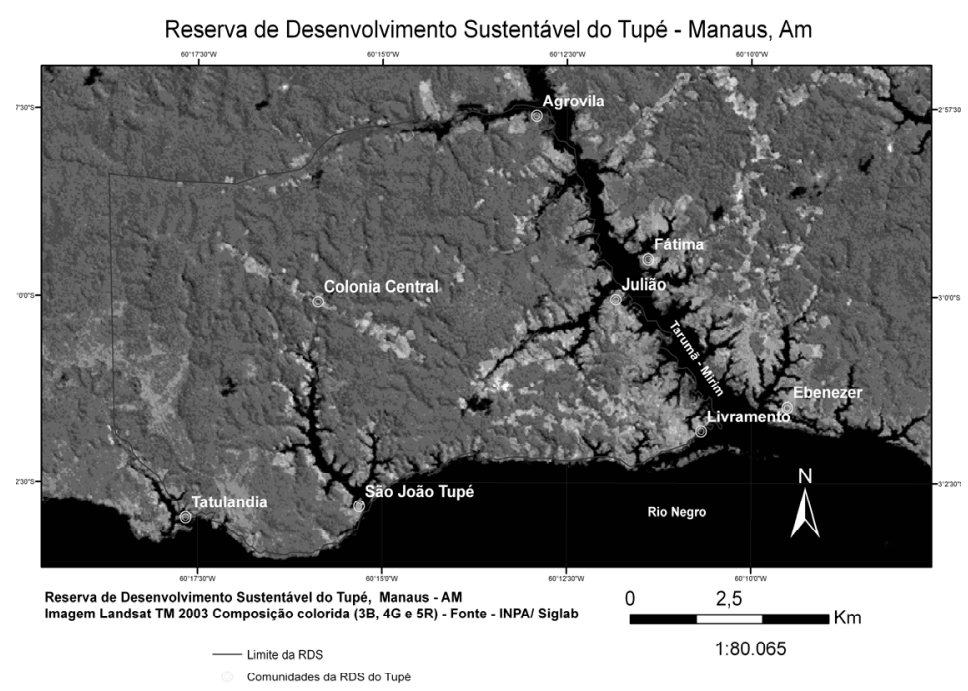

Figura 3 - Comunidades da RDS do Tupé

\section{Trançando a perspectiva teórica: os estudos de percepção ambiental}

Para entrançarmos os conhecimentos sobre o Tupé, procuramos uma modalidade de pesquisa que pudesse revelar esse universo de significados, aspirações, valores e atitudes que seus moradores têm sobre esse lugar.

Os estudos envolvendo percepção ambiental tiveram maior estruturação durante a década de 70 a partir da criação do Grupo de Trabalho sobre a Percepção do Meio Ambiente, pela União Geográfica Internacional (UGI), e do projeto 13: Percepção da Qualidade Ambiental, no Programa Homem e Biosfera, da UNESCO, contemplando os vários métodos, sugerindo a importância de tais estudos para o planejamento, como parte integrante das análises multidisciplinares.

A expressão percepção do ambiente segundo Whyte é “(...) a tomada de consciência e a compreensão pelo homem do ambiente no amplo sentido. Ela deve ser considerada bem mais abrangente 
que uma percepção sensorial individual, como a visão ou audição" (WHYTE, 1978, p.18).

Ainda na década de setenta, esses estudos se intensificam e se inseriram dentro da geografia, em um grande movimento que recebeu o nome de "Geografia Humanística". Utilizando as palavras de Mello: a Geografia passou a utilizar a experiência vivida como instrumento de investigação, objetivando interpretar o sentimento e o entendimento dos seres humanos a respeito do espaço e do lugar (MELLO, 1990, p.92).

Entretanto, a geografia humanística tem raízes antigas, marcos fundamentais no desenvolvimento e na consolidação dessa linha de pesquisa ambiental (AMORIM, 1999). Podemos citar os trabalhos de Sauer (1925) que enfatiza os estudos sobre as paisagens, percebidas e vividas pelos homens, Dardel (1952) que expressa a importância das experiências vividas e da noção de valor na curiosidade e nas indagações sobre a Terra, dentre outros trabalhos.

Em sua obra ' $L$ ' Homme et La Terre - Nature de la realité geographique" publicada em 1952, Eric Dardel procurou mostrar a geografia do ponto de vista geral de uma reflexão sobre as atitudes humanas no mundo, segundo ele: decifrar os signos ocultos da Terra:

O conhecimento geográfico tem por objetivo explicitar estes signos, isto que a Terra revela ao homem sobre sua condição humana e seu destino. Isto não é primeiramente, um atlas aberto diante dos seus olhos, é um apelo que vem do solo, da onda ou da floresta, uma chance ou uma recusa, um poder uma presença (DARDEL, 1952: p.2).

Para Holzer (1992) em toda a historia da Geografia Humanística, nos deparamos com conceitos inaugurados por Dardel: o caráter intersubjetivo da apreensão da natureza, os conceitos de lugares enquanto lugares de vida, a tentativa de compreensão do mundo através da percepção dos indivíduos.

Neste trilhar, nos deparamos com os trabalhos do geógrafo Yi-fu Tuan que evidencia em seus estudos a relação das pessoas 
BARROS, S. et al. Tecendo o Tupé: um estudo sobre percepção e ...

com a natureza e dos seus sentimentos e idéias sobre os espaços, paisagens e lugares a fim de melhor entender o homem e sua condição.

Em seu livro Topofilia ele desenvolve como temática central "o conceito de vivido concernente aos laços topofílicos, ou seja, a todo tipo de ligação afetiva entre os seres humanos e o meio ambiente, vínculos esses que diferem profundamente em intensidade, sutileza e modo de expressão" (TUAN, 1980, p.107).

Em outro trabalho "Espaço e Lugar" (1980) Tuan explora o conceito de lugar e, por complementaridade e antagonismo, o conceito de espaço. O lugar tem uma complexa teia de formulações, ele é vivido, concebido, mítico sagrado, dotado de valor, é o lar. O espaço é entendido como aberto, livre, vulnerável, sendo desprovido de valores e de ligação afetiva.

Assim, nosso trabalho será norteado pelos conceitos geográficos propostos nos estudos da Geografia Humanística, procurando o "lugar" - espaço de identidades - Tupé do ponto de vista dos seus moradores.

\section{Vozes do Tupé - moradores tecendo seus lugares}

Em nosso trabalho tivemos convívio direto com os moradores do Tupé e pudemos participar de suas vidas no seu cotidiano, compartilhando de seus sentimentos e vivências.

A comunidade São João do Tupé tem contato direto com o Rio Negro, que propicia, no período da vazante, o aparecimento de praias, muito procurada por turistas. Já a comunidade Colônia Central está localizada no meio da floresta, sendo a agricultura familiar o traço mais marcante dessa localidade.

As principais atividades econômicas são a agricultura, a pesca, e na comunidade São João do Tupé o turismo de massa. Parte das famílias retira sua renda de aposentadorias, de salários como funcionários públicos de instituições municipais. As famílias assalariadas conjugam seu trabalho com o plantio e o cuidado da roça, o fabrico da farinha e também o artesanato. Outros somente 
BARROS, S. et al. Tecendo o Tupé: um estudo sobre percepção e ...

vivem de suas plantações, ou recebendo auxilio financeiro dos filhos que moram em Manaus.

\section{A vida no "interior"}

Permeia nas entrevistas sempre a necessidade de estar no "interior", em contato com a natureza. Fica importante evidenciar que os moradores nasceram no Tupé, ou em cidades do interior do Amazonas ou em alguma outra pequena cidade da região Norte ou Nordeste. Todos passaram um tempo por Manaus, à procura de emprego, estudo para os filhos, tratamento de saúde para seus familiares, entretanto não conseguiram se "adaptar" ao ritmo da cidade grande.

Nasci perto do Acre e vim pra Manaus faz 30 anos, mas eu nunca me acostumei lá não. Eu gosto mesmo é daqui da mata. Aqui eu me sinto à vontade. Aqui eu tenho segurança. Eu me sinto muito bem aqui (Morador da Colônia Central, 62 anos).

Essas pessoas foram "compelidas" a deixar essa vida em suas cidades de origem e a procurar na cidade de Manaus (em franco crescimento demográfico, com inúmeros problemas sócioambientais) seu "espaço". A falta de especialização para trabalho na cidade, a pouca ou nenhuma escolaridade, dificultaram essa nova realidade. Muitos marginalizados procuraram re-apropriar, a resgatar hábitos "tradicionais", procurando seu lugar no interior.

A experiência com o ambiente Manaus surge como sendo negativa. A falta de oportunidades ligadas ao emprego, a grande população da cidade, a poluição, os ruídos provocados pelos carros:

Aqui eu saio na mata e posso ficar dias andando, não sinto medo nenhum, mas em Manaus... eu posso sair na rua que eu já fico agoniado (Morador da comunidade Central, 65 anos).

Durante a análise dos depoimentos, observamos através dos relatos que a afeição pelo lugar Tupé se dá pela paz que ele 
BARROS, S. et al. Tecendo o Tupé: um estudo sobre percepção e ...

proporciona. Muitas vezes esse lugar é parecido aos lugares dos tempos de infância, evidenciando uma identificação com essa área:

Eu fui nascido no interior, sou raiz do interior, e no interior é que eu me sinto bem. Eu gosto muito do interior, de estar no meio do mato... Isso aqui é a minha vida (Moradora da comunidade Central, 37 anos).

O sentimento com o lugar se afirma quando são resgatados instantes do passado atraentes e que evocam imagens representativas, como mesmo afirma Tuan "a história é responsável pelo amor à terra natal" e ainda segundo ele "a consciência do passado é um elemento importante no amor pelo lugar” (1980, p.115-114).

Esse sentimento de enraizamento dos moradores do Tupé contribui para a formação da identidade desse lugar, carregado de satisfação e felicidade de ser desse lugar, morar, e ter contato íntimo com a natureza.

\section{Tecendo relações com a natureza}

A paisagem percebida pelos moradores é experienciada e impregnada de historicidade e símbolos - a roça, a produção dos alimentos, o rio, a pesca, a calma. Os valores atribuídos à paisagem denotam os significados traduzidos em identidades, inseparáveis da convivência diária com a natureza.

Essas imagens mostram uma realidade que é vivenciada pelos seus moradores. Na fotografia aérea (Fig. 4a), os elementos que surgem são o rio, a água a floresta. Já, no desenho dos moradores (Fig. 4b), os mesmos elementos da paisagem aparecem, contudo, preenchidos com a vida, o dia-a-dia dos moradores. As casas, a ligação feita entre as casas, a igreja, o campo de futebol, o cemitério da comunidade conectam os ambientes do ser humano e da natureza. 


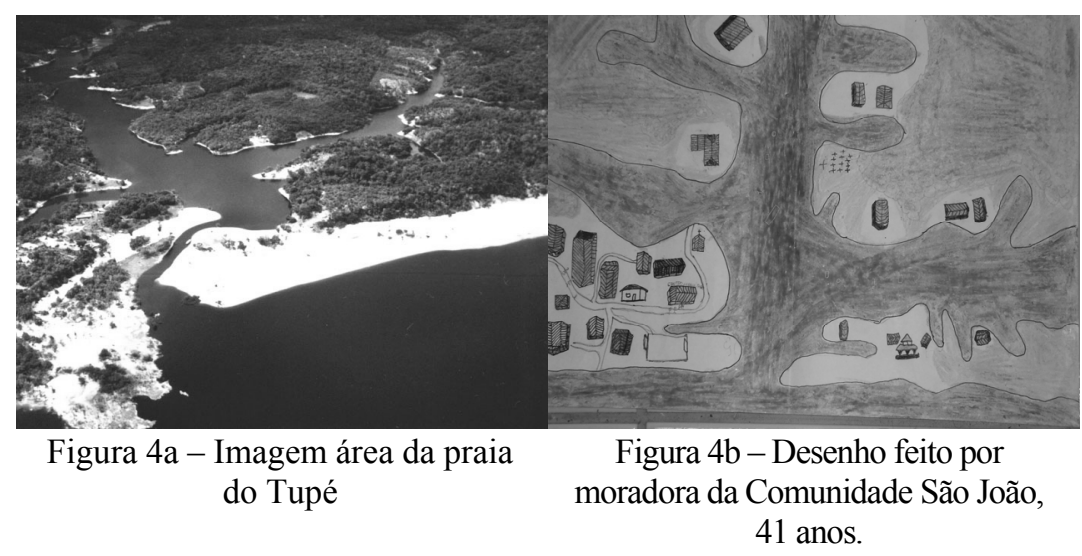

Para Oliveira (1998, p. 54):

O espaço onde vivemos, nos movimentamos, nos envelhecemos acontece em uma história e em uma geografia. É um espaço heterogêneo, pois não habitamos no vazio, mas com cores de nuances de luz e sombras e muitas vezes de penumbra. Nosso espaço, todavia, é composto de espaços reais e irreais.

Nesta confluência, considera-se a importância afetiva do lugar para a população, ultrapassando o entendimento do espaço estritamente a partir de seus atributos físicos, "podemos dizer que a percepção de uma paisagem é uma questão de olhos e coração, isto é, campo de visão e campo de afeição, de olhar e sentir o espaço e sentir este mesmo espaço" (LIMA, 1990, p. 74).

Nas conversas, nos desenhos, fotografias destacam-se um elemento importante no quadro de percepções, a relação dos moradores com a água. Os cursos d'agua, o Rio Negro, o período da chuva, o período da seca são presentes nos seus modos de vida como dimensões fundamentais na suas vidas cotidianas.

Quando foi pra eu morar aqui, tinha na minha cabeça que tinha de ser perto do igarapé. Eu queria ficar perto do igarapé, eu sou igual sapo, gosto do meu banho (Morador da comunidade Central, 62 anos). 
A imagem do homem na Amazônia é comumente associada à água, havendo, nesse sentido, uma relação intersubjetiva entre o homem amazônico e a água. São Homens Anfibios (FRAXE, 2000), Povo das Águas (PORRO, 1995) para designar as populações amazônicas. Na obra de Leandro Tocantins "O Rio comanda a Vida" podemos ver um pouco dessa relação:

$\mathrm{O}$ homem e o rio são os dois mais ativos agentes da geografia humana da Amazônia. O rio enchendo a vida do homem de motivações psicológicas, o rio imprimindo à sociedade rumos e tendências, criando tipos característicos na vida regional (...) o rio, sempre o rio, unido ao homem (...) onde a vida chega a ser, até certo ponto, uma dádiva do rio, e a água uma espécie de fiador dos destinos humanos TOCANTINS, 2000, p. 277-278).

Nos depoimentos dos moradores do Tupé, ao falarem sobre aquilo que mais gostam do Tupé, a água se fez presente em todos os momentos:

Gosto de pescar. À noite é a melhor coisa pra fazer. Pego minha canoa e vou embora. Jaraqui é o que mais tem aqui (Morador da Comunidade São João, 56 anos).

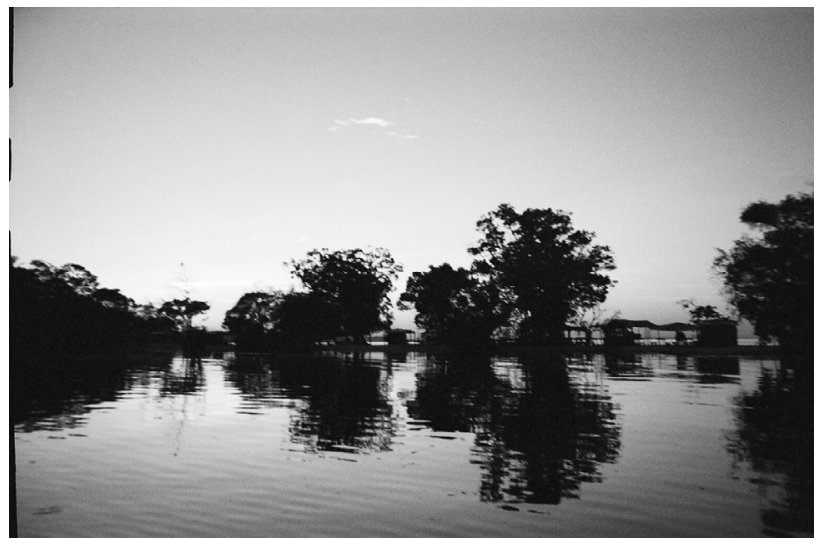

Figura 5 - Fotografia de Morador: "essa paisagem é uma maravilha, é isso. Eu vejo essa beleza todos os dias da minha casa", 52 anos.

Fonte: Barros, 2005. 


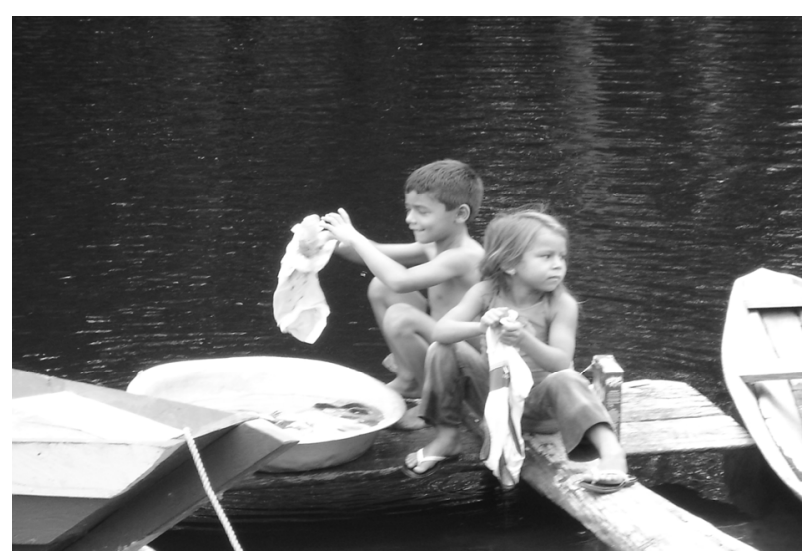

Figura 6 - Crianças do Tupé - lavando suas roupas no lago do Tupé. Fonte: Barros, 2005.

Nosso trabalho, em grande parte feito durante o ano de 2005, presenciou a chamada "seca" que foi noticiada em todo o Brasil e foi sentida pelos moradores. Muitos deles ficaram no período da seca em Manaus, contudo outros ficaram no Tupé, passando inúmeras dificuldades, dentre elas a falta de água potável, falta de alimentação, assistência médica:

Teve gente que ficou isolado aqui dentro, porque não tinha como sair daqui. Quem saiu antes da seca, não conseguiu voltar, ficou lá pra Manaus (Moradora da comunidade Colônia Central, 46 anos).

Durante os quase três meses de isolamento, o auxílio do governo com alimentação chegou apenas uma vez e quase no fim desse período:

Eu olhava pros meus filhos e não sabia o que fazer. A gente ia comer o que? Não tinha como sair (Morador da comunidade Colônia Central, 38 anos).

Um aspecto da natureza é muito presente, sobretudo aos moradores da Comunidade São João: a presença das praias fazendo 
BARROS, S. et al. Tecendo o Tupé: um estudo sobre percepção e ...

com que parte dos moradores se dedique às atividades turísticas, principalmente as de recepção.

A praia é a coisa que eu mais acho bonita aqui, não tem como não admirar. Quem vem aqui não esquece (Moradora da comunidade São João, 36 anos).

Entretanto, o turismo vem ocorrendo de forma desordenada, e o que poderia trazer renda para os comunitários beneficia somente alguns:

Os barcos chegam cheios de gente de Manaus, mas eles acabam trazendo tudo, sabe tudo que eles vão comer e beber. Não compram nada da gente. Eles só sabem da praia. Acho que nem sabe que aqui tem gente morando (Morador da comunidade São João, 40 anos).

Os barcos, conhecidos como "recreios" chegam às noites de sábado, com som alto e permanecem assim durante toda à noite. A demanda turística é na sua maioria vinda de Manaus (Fig. 7).

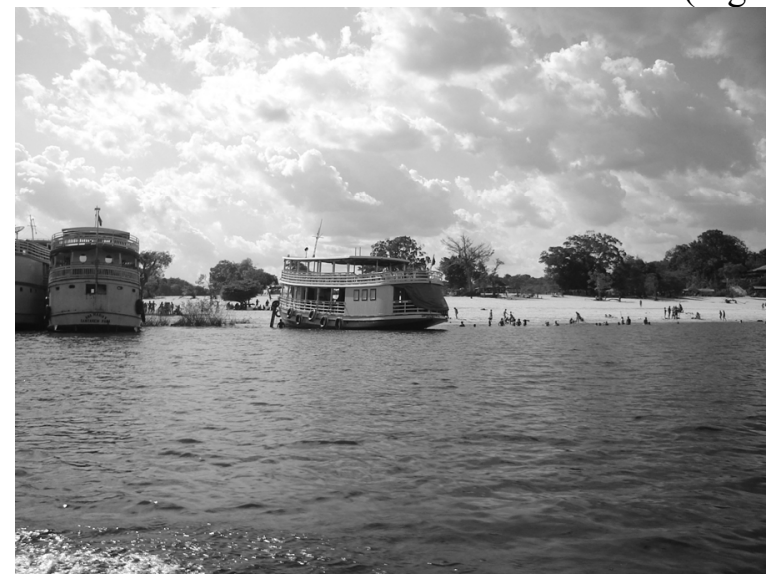

Figura 7 - Praia do Tupé e os turistas. Fonte: Barros, 2005.

Porém os moradores anseiam pelo momento em que possa haver harmonia entre a atividade turística, a natureza e os moradores. Inclusive, o turismo é apontado pela grande maioria 
BARROS, S. et al. Tecendo o Tupé: um estudo sobre percepção e ...

dos comunitários de São João como sendo a solução para o futuro da comunidade.

O processo de "ordenamento" do turismo no Tupé tem ocorrido de maneira tímida, já que essa área se tornou uma Unidade de Conservação no ano de 2005 e não possui plano de manejo. Contudo, uma proposta de turismo para o Tupé precisa de respeito ao ambiente e aos moradores, e ainda precisa considerar as realidades regionais e locais, na promoção do desenvolvimento sócio-espacial.

A ligação com a terra, com as plantações, com a floresta também são características marcantes dos moradores do Tupé. O significado da terra ganha grande importância, para aqueles que são tradicionalmente agricultores.

Para Tuan (1980, p. 111)

$\mathrm{O}$ apego à terra do pequeno produtor ou camponês é profundo. Conhecem a natureza porque ganham a vida com ela. (...) Para o trabalhador rural a natureza forma parte deles (...) A topofilia do agricultor esta formada desta intimidade física, da dependência material e do fato de que a terra é um repositório de lembranças e mantêm a esperança.

Essa relação com a terra, com as plantações pôde ser vista nos depoimentos dos moradores:

Gosto mesmo é da minha plantação. Aqui é bom você plantar e depois colher, foi isso que me deixou ficando aqui, tinha vontade de esperar crescer e colher o que eu plantava (Morador da comunidade Colônia Central, 45 anos).

No Tupé, os produtos resultantes dessas atividades agrícolas destinam-se ao consumo familiar e à venda do excedente. A atividade agrícola está apoiada no sistema de "agricultura itinerante" (roças), onde parte da floresta é derrubada, queimada, plantada (principalmente com mandioca, macaxeira, banana, às vezes com maxixe, abóbora, etc.) e, posteriormente, deixada em pousio. 
BARROS, S. et al. Tecendo o Tupé: um estudo sobre percepção e ...

Um outro sistema é a atividade agrícola realizada ao redor da residência, que se caracteriza pelo cultivo de frutíferas, hortaliças, plantas condimentares, medicinais e ornamentais.

A mata também é considerada um sistema de produção, devido a realização de atividades extrativistas caracterizadas pela coleta de frutos, ervas medicinais e cipós, caça e extração de madeira.

Analisando a lavoura camponesa, Woortmann se refere ao sítio como "um sistema de espaços articulados entre si". Sendo que esse sistema não é "algo dado", mas um complexo construído ao longo da vivência de uma família (1983, p. 76).

Isso aqui é a minha alegria. Era tudo o que eu queria na minha vida. É eu plantar e depois ver desse jeito, bonito (Moradora da comunidade São João,52 anos).

Nesse relato, é possível entender, com base em TUAN (1980, 1983), que este tipo de topofilia está formada da intimidade física, da dependência material e do fato de que a terra é um repositório de lembranças e mantém a esperança. Tais aspectos engendram afeição e um profundo apego pelo lugar.

No domínio casa-quintal podemos ainda observar a expressão dos símbolos da comunidade: pomar carregado, a variedade e a quantidade dos animais criados que permanecem no terreiro da casa; os bichos de terreiro são sinais de trabalho bem sucedido que garantem a aquisição e manutenção desse domínio ou status.

Na comunidade Central, parte dos moradores se dedica à produção da farinha, tendo em vista que é alimento básico.

Aqui tem a mandioca "bolão", a mandioca branca, tem bem uns quatro tipos de mandioca (Morador da comunidade Colônia Central, 62 anos).

A farinha de mandioca é preparada na casa de farinha, pequena construção que abriga o forno e diversos utensílios, peneiras, tipiti ou prensas. Para Pinton \& Emperaire (2000, p. 62) "a propriedade desta casa de farinha constitui um investimento 
BARROS, S. et al. Tecendo o Tupé: um estudo sobre percepção e ...

importante e é um sinal de estabilidade econômica para as comunidades".

Ficam evidentes os valores de familiaridade da vida na mata e são comuns as referências pertinentes aos seus lugares, traduzidos nas formas de trabalho, de vizinhança, caminhos, representações e manifestações de identidade.

Compor essa "terra" não exibe um significado exclusivamente econômico, mas, sobretudo de moral e de honra, relacionados à autonomia e independência inerentes à propriedade de um pedaço de terra própria.

A espiritualidade e o convívio social também estão presentes no dia a dia dos moradores do Tupé. Ao serem questionados sobre o que mais gostam no Tupé, além do rio, da roça, a religiosidade, a proximidade de Deus foi relatada pelos moradores. A comunidade São João tem sua igreja católica e também crente, como são denominadas as igrejas protestantes. Na colônia Central será construída a igreja católica, as reuniões são feitas no chamado "barracão", lugar aonde também são feitas as reuniões, encontros e festas (Fig. 8).

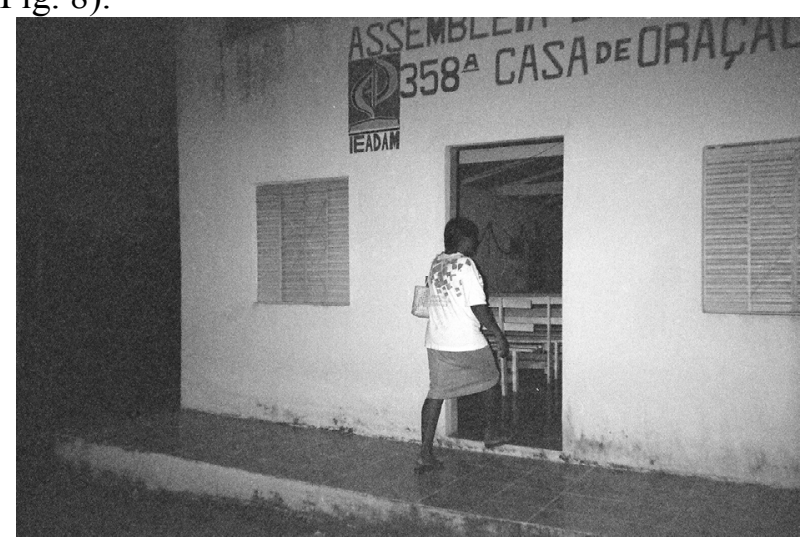

Figura 8 - Fotografia de moradora da Comunidade São João, 37 anos Momento com Deus. Fonte: Barros, 2005.

Em alguns dos depoimentos, a proximidade com a natureza significa também estar próximo de Deus: 
BARROS, S. et al. Tecendo o Tupé: um estudo sobre percepção e ...

Aqui eu vejo a mão de Deus que criou toda essa beleza. A gente ta aqui pra cuidar disso, pra que ninguém destrua o que foi feito pelas mãos divinas (Moradora da comunidade São João, 40 anos).

As festividades, também surgem como momentos de encontros com os moradores. A comunidade São João comemora o dia de São João (Figura 9), com uma festividade que ocorre há cinco anos.

A festa pra mim é onde a gente esquece os problemas e encontra todo mundo junto pra se divertir (Morador da comunidade São João, 51 anos).

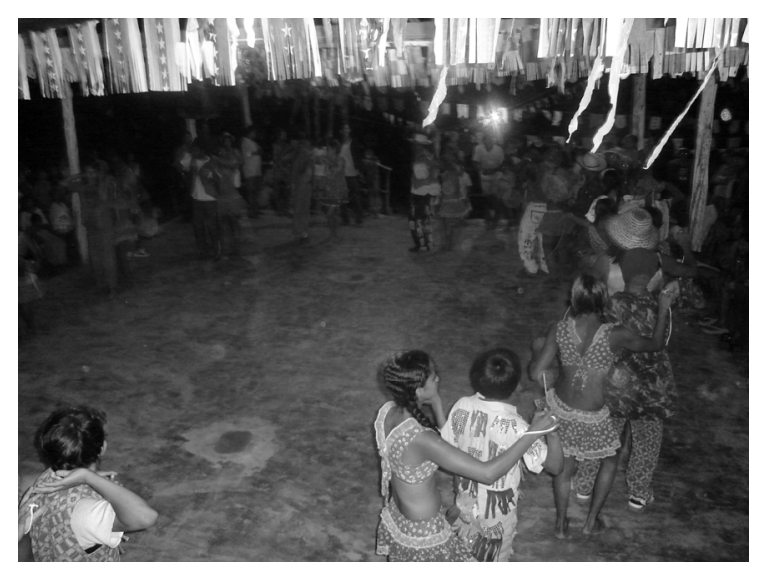

Figura 9 - Momento da festividade. Fonte: Barros, 2005.

Os moradores também foram convidados a contar sobre aquilo que eles não gostam no Tupé, aquilo que os incomoda, que desperta emoções ou sentimentos adversos, topofóbicos. Emergiram nesse momento os principais problemas enfrentados pela comunidade.

Todos os depoimentos chamaram atenção à deficiência com relação à falta de assistência médica. Somente a comunidade São João dispõe de um agente de saúde, a Colônia Central não dispõe de nenhuma assistência nesse sentido. A falta desses serviços 
BARROS, S. et al. Tecendo o Tupé: um estudo sobre percepção e ...

básicos, principalmente nos setores da saúde e educação, incita as famílias a se instalarem na cidade:

É obrigação do governo, a gente tem o direito de ter o mínimo aqui, pelo menos um agente de saúde. A gente não tem nada, estamos esquecidos aqui. Só lembram da gente quanto é tempo de eleição (Morador da comunidade Colônia Central, 51 anos).

Outro problema citado pelos moradores é a falta de escola ou de uma abrangência maior do ensino na Comunidade São João. A Comunidade São João dispõe de escola que atende o ensino fundamental.

A gente que é mais velho tudo bem, mas e os meus filhos? Eu não quero que eles fiquem sem estudo. Do jeito que tá, vamos ter que voltar pra Manaus pra que eles estudem (Morador da comunidade São João, 56 anos)

Se a gente for pra cidade fica pior, porque quem estuda já não encontra emprego, imagina quem não tem estudo! (Morador da comunidade Colônia. Central, 51 anos).

A falta de energia elétrica também foi mencionada pelos moradores de ambas as comunidades.

Sabe, hoje eu não posso guardar nada aqui. Estraga tudo. A única coisa que não estraga é a farinha (Moradora da comunidade Colônia Central, 48 anos).

\section{Tecendo o lugar Tupé}

Criamos lugares com os quais nos identificamos, pois fazem parte de nós mesmos. Em nosso estudo, procuramos a "identidade" do Tupé, ou seja, como é esse lugar, o que ele significa para seus moradores?

Pudemos perceber através dos depoimentos que existe uma sintonia entre os moradores e a paisagem que é transformada em um lugar especial, espaço vivido, essencial para a vida e 
BARROS, S. et al. Tecendo o Tupé: um estudo sobre percepção e ...

experienciado cotidianamente. São significados que não podem ficar de lado, ao nos referirmos aos lugares do Tupé.

As vidas dos moradores do Tupé não são vistas dentro da cidade de Manaus. Apesar das dificuldades em permanecer no Tupé ligadas à falta de condições de trabalho, falta de educação e assistência médica, não sentem vontade de sair de lá. Os depoimentos mostram que precisam ficar próximos à natureza, no "interior"; sendo que na cidade, sentem-se desprotegidos, angustiados.

Esses moradores construíram ali suas vidas, suas famílias, seus lares e construir uma história de vida nesta paisagem dá aos moradores o sentimento de pertencer a esse lugar. Assim, convergimos com as idéias de Relph:

Nos não somente apreendemos espaço através de nossos sentidos, mas vivemos nele, nele projetamos nossa personalidade e a ele somos ligados por limites emocionais. Espaço não é exatamente percepcional, sensorial ou representacional: ele é vivido. E porque ele é vivido deve haver tantos espaços quantos forem as experiências espaciais ou colocando diferente, como nossa consciência de espaço se modifica, então os espaços onde estamos mudam para nós suas qualidades e significações (RELPH, 1979, p. 8).

A sensação de tranqüilidade, calma, paz, o clima agradável, são encontrados nesse lugar, segundo os valores atribuídos à paisagem pelos moradores.

Este sentimento relativo ao lugar enraíza-se ou não nas pessoas, apresentando intensidades e significados que se transformam ao longo dos anos em expressões marcadas pela afetividade que as levam a agir e reagir ou não-agir sobre o meio ambiente, influenciadas em parte pelo modo de perceber, interpretar, avaliar e valorar os resultados de suas experiências com o espaço vivido (GUIMARÃES, 2006, p.123). 
BARROS, S. et al. Tecendo o Tupé: um estudo sobre percepção e ...

Muitos turistas e pesquisadores vão até o Tupé e o percebem de maneira fragmentada, conforme o foco de sues interesses individuais. $\mathrm{O}$ turista geralmente conhece o Tupé pela existência da praia, os pesquisadores vêem o Tupé sob o ponto de vista da biodiversidade, dos lagos de igapó, das espécies de árvores da floresta, da necessidade de conservação, entre outros aspectos.

Contudo, procuramos chamar a atenção a esse mesmo Tupé do ponto de vista de quem mora nele. Compondo esse ambiente, existem as histórias, as vivências de pessoas que tecem o Tupé diariamente e conhecem e se identificam com esse lugar, construindo suas próprias identidades territoriais e pessoais a partir deste espaço vivido.

Essa vivencia é, antes de tudo, fruto da história e da cultura materializada em diversos momentos e num processo de contínuas transformações, conduzidas principalmente pelo ritmo do turismo, se traduzem em diversas paisagens carregadas de significados múltiplos.

Recebido em maio de 2007

Aceito em julho de 2007 